\title{
Maintaining the Pace
}

After the implementation of so many innovations over the last four years, one might think Respiration should enter a phase of consolidation. Not so! One year after the introduction of the new section 'Interventional Pulmonology', we are proud to announce, that the newly founded European Association for Bronchology and Interventional Pulmonology (EAB) have decided to make this section their home. We welcome the new society as this move is clearly of mutual benefit. An international journal such as Respiration reaches a wider readership and the society gets an immediate head start in a well-established journal with their articles being citable from the start! For details, see the editorial by Heiner Becker, a founding member and first president of the EAB. We wish this new society all the best for the future!

Despite this addition, the overall vision of Respiration remains unchanged. The emphasis remains on general thoracic medicine covering all aspects in the field. The ultimate editorial decision to publish an article lies with the Editor-in-Chief.

The popular Thematic Review series has covered COPD last year. As its articles repeatedly mentioned that smoking is the main culprit, it only seems logical to center the next series on how to combat this culprit. I was very lucky indeed to be able to recruit Karl-Olav Fagerström as the series editor for this 2002 series on 'Tobacco Dependence'. It also reflects the clear aim of Respiration to attract more original papers on smoking cessation and on the ill effects of smoking. These topics often get published in the specialized literature and are therefore not frequently read by chest physicians. Submit them to us! For details on the series, please read Karl-Olav Fagerström's stimulating editorial preceding the first article.
And how are we doing as a journal in a competitive market? Well, the accompanying graph (fig. 1) is selfexplanatory. A year ago I could report on a $100 \%$ increase in manuscript submissions; this year, another 50\% has taken place, making it a 2.5-fold total increase over 1996! This allows us to keep the acceptance rate for original articles at a maximum of $40 \%$, possibly aiming at $35 \%$, with the policy on case reports becoming even stricter where we currently have to reject about $90 \%$. So, please read the signs of the time and only submit exceptionally good case reports, which means: absolutely new findings or very rare diseases. In the latter case, the discussion must include full coverage of the existing literature. In 2002 we will continue to print the same number of pages in 6 issues. Depending on the volume of additional material from the $\mathrm{EAB}$, we might have to increase the number of issues, but for the time being, we shall stick to the priority of quality over quantity.

During 2001 Respiration was available full text on line for free. This special was highly successful but has come to an end, as Respiration like most journals mainly depends on income from paid subscriptions. The unanimously accepted suggestion at our last editorial board meeting in Berlin was that the current volume will be available on line for free in abstract form, as full text on subscription only, but preceding volumes will continue to be available free on line, in full text.

The work of the Editorial Board has again been outstanding. A special thanks goes to all Editorial Board members, but also to the numerous external reviewers, who helped with manuscript reviewing. The ever-increasing number of submissions has necessitated an increase in the numbers of associate editors as of this year. It is my

\begin{tabular}{ll}
\hline KARGER & (c) 2002 S. Karger AG, Basel \\
Fax +4161306 12 34 & $0025-7931 / 02 / 0691-0002 \$ 18.50 / 0$ \\
$\begin{array}{l}\text { E-Mail karger@karger.ch } \\
\text { www.karger.com }\end{array}$ & $\begin{array}{l}\text { Accessible online at: } \\
\text { www.karger.com/journals/res }\end{array}$
\end{tabular}




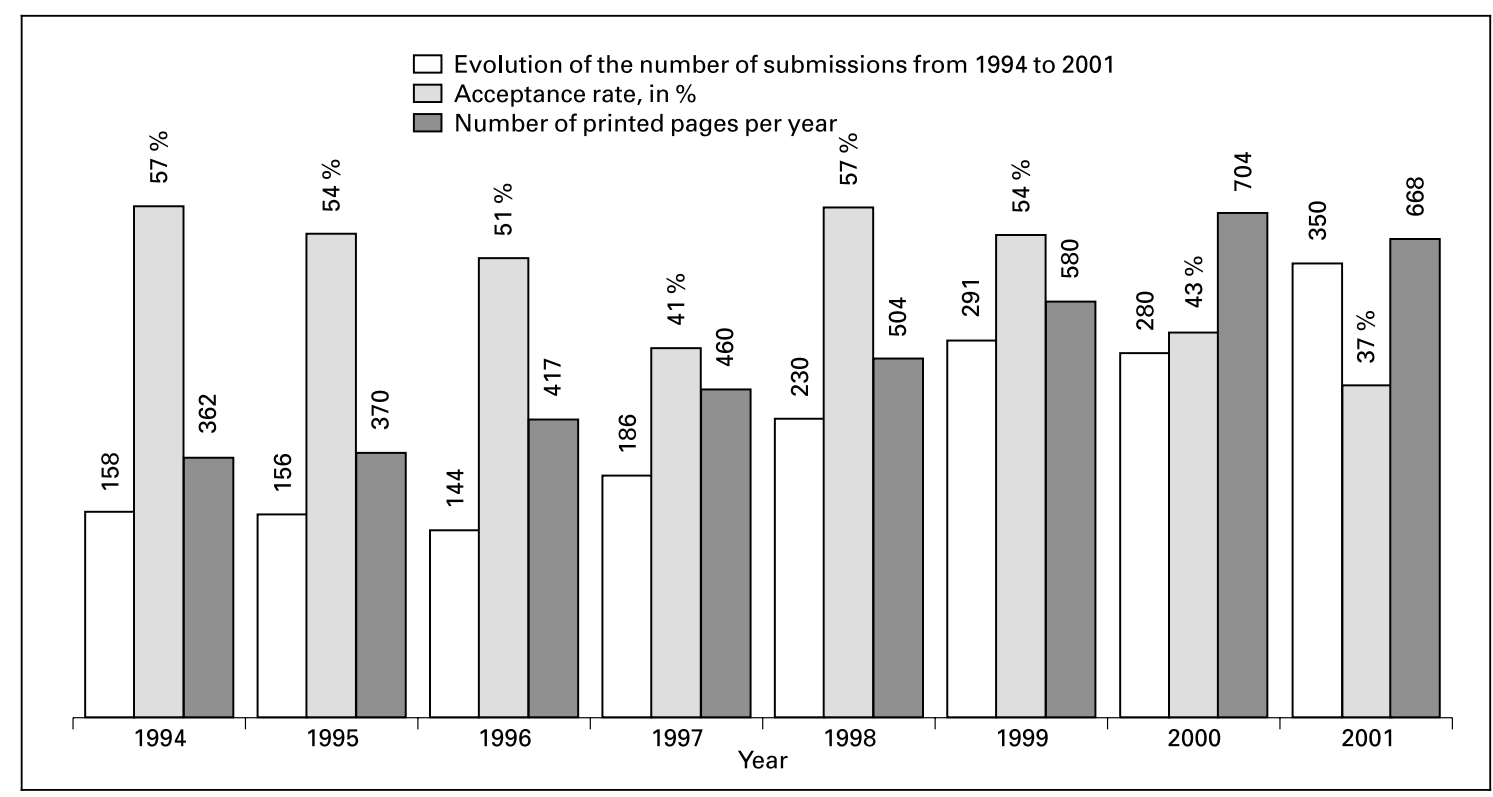

Fig. 1. Evolution of the number of submissions, acceptance rate and number of printed pages per year from 1994 to 2001 .

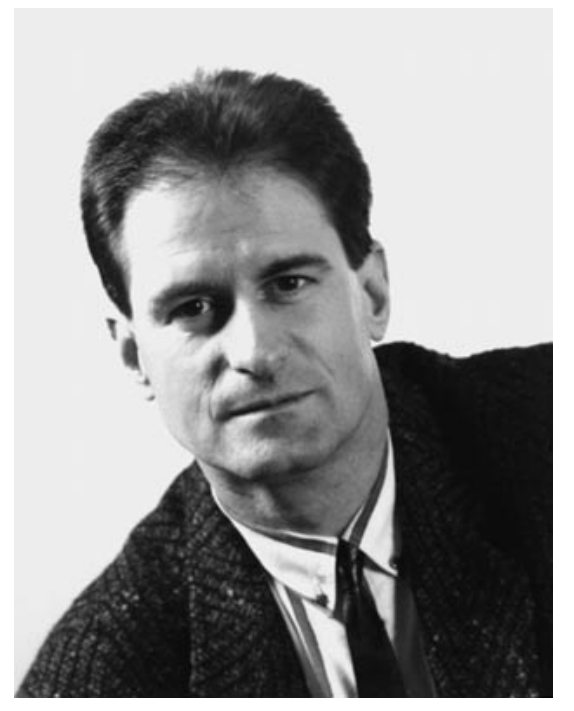

Fig. 2. Professor H.D. Becker, Heidelberg.

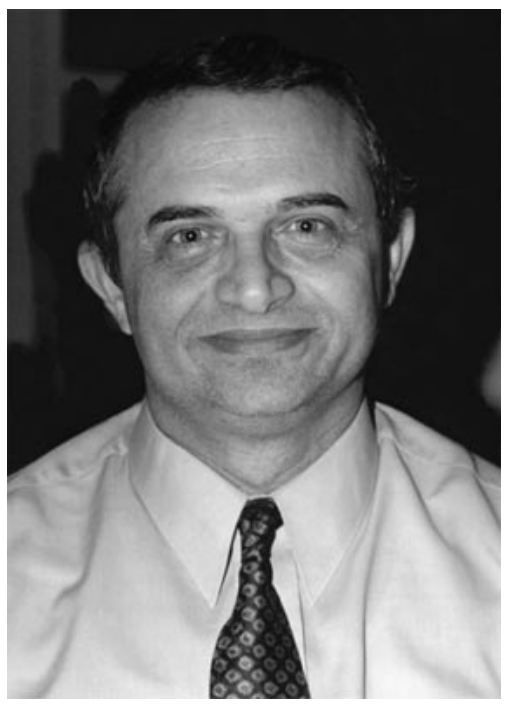

Fig. 3. Professor D. Bouros, Heraklion.

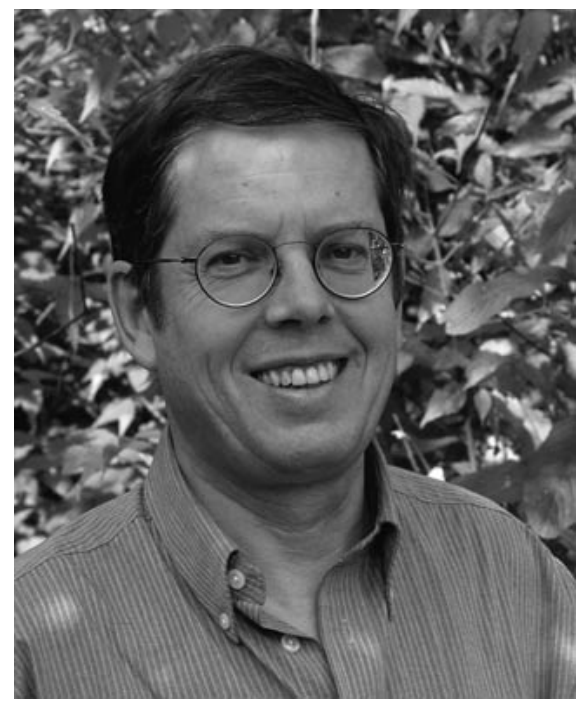

Fig. 4. Professor E.W. Russi, Zürich. pleasure to announce three outstanding pulmonologists as new associate editors: Prof. Heiner Becker from Heidelberg for Interventional Pulmonology, Prof. Demosthenes Bouros from Heraklion, and Prof. Erich W. Russi from Zürich, both for general pulmonology (fig. 2-4). This brings the number of associate editors to ten, which will help us to further reduce manuscript handling time.
Dear reader, with this ongoing evolution, it goes without saying that we at the journal have to maintain the pace in order to meet the short-term goal of securing Respiration's place among the top specialist journals in thoracic medicine.

C.T. Bolliger, Cape Town 